\title{
The Contextual Learning Approach in Engineering Education
}

\author{
Ida Kukliansky*, Shai Rozenes ** \\ * Department of Industrial Engineering and Management, School of Engineering, Ruppin Academic \\ Center, Emek-Hefer, Israel \\ ** Department of Industrial Engineering and Management, Afeka Tel Aviv Academic College of \\ Engineering, Israel
}

\begin{abstract}
This study presents a learning approach that educates Industrial Engineering and Management students to perform their future job more successful. This approach embeds a practical project within the learning program. The theoretical framework of our learning process is contextual learning, which claims that a learning process occurs when students link new formal knowledge with real-life experience. The project stimulates the student to implement the theoretical knowledge in a practical environment. This approach was applied in two important academic courses: project management and new service development. 129 engineering students, participants of this study, had to implement the academic know-how into the embedded project. The study utilizes a quantitative tool to measure the students' response to the approach. This evaluation tool included 'preferred' and 'actual' questionnaire forms. The results indicate that the majority of the students were satisfied with their learning environment; their actual form rank was at least like the preferred form rank.
\end{abstract}

Keywords: Engineering education; hands-on-experience; contextual learning; active learning

\section{Introduction}

The aim of this paper is to present a methodological academic training framework for the students studying Industrial Engineering and Management (IEM) during undergraduate studies. The study reveals an embedded real-life project that enables the students to gain both profound know-how and experience during their studies. This approach was applied in two academic courses: project management and new service development. These disciplines are expanding within many engineering and business activities and can facilitate strivings toward successful accomplishment of engineering projects and sustainable entrepreneurships. Therefore, many academic institutes teach these programs. In order to manage projects processes successfully, a training process is needed (Rozenes \& Vitner, 2009).

The theoretical anchor of the teaching process presented in this paper is contextual learning, which claims that a learning process occurs when students link new formal knowledge with real-life experience. This approach, developed at the beginning of the 20th century by John Dewey (Dewey, 1916), adapts the learning process to the experiences and interests of the learner. Learning is understood to be more effective when new material is tied to previous knowledge, and involves the learner in the learning process. The key to successful learning lies in the connectedness of the learned knowledge to what seems meaningful to the learner (Caine \& Caine, 1991). Much research supports this type of learning and argues that it is significant for the learners (Klassen, 2006). Roth \& Roychoudhury (1993) found a link between contextual learning and learner's motivation. According to Binnie (2004) contextual learning is very efficient, especially for raising learners' interest and increasing students' participation in the learning process. In addition, contextual learning elements not only increase the learner's motivation for the study task, but also provide cognitive support to see the similarities and differences and to organize ideas (Rivet \& Krajcik, 2008). Contextual learning emphasizes higher-level thinking, knowledge transfer across 
academic disciplines, and collecting, analyzing and synthesizing information and data from multiple sources and viewpoints (Smith, 2000). Contextual learning facilitates learning in which students employ their academic understanding and abilities in a variety of out-of-school contexts to solve complex, real-world problems, both alone and in various groups (Shelley-Tolbert et al., 2000). Applying the context-based approach to learning was also found to be effective for engineering students who learn how to analyse experimental data, in the context of the laboratory, rather than learning data analysis skills in a non-contextual form such as in a mathematic-based course (Kukliansky \& Eshach, 2014).

\section{Methods}

\section{The education methodology}

The common teaching practice is the combination of lectures with tutorials. The education methodology combines lectures with life experience that facilitate the learning process. The education process combines academic theory and practice. The program is conducted as a workshop, in which all the participants take part in discussions, while performing genuine assignments. Contextual learning is applied, while each participant is required to choose a real-life project to facilitate the learning process. Creativity and innovation are important during the entire process. The project is presented during the workshop, to illustrate the implementation of tools and techniques within their organizational environment.

The program consisted of fourteen weekly four-hour sessions. The teams of the participants were required to implement each program subject into their suggested project. The projects were executed in different knowledge areas such as education, healthcare, hospitality, entertainment, wholesale/retail and food. Based on contextual learning, these projects were performed as real-life projects. For example, a project in the food sector was to construct a new pub for elderly people, whereas a project in the hospitality sector was to build a special motel catering to honeymooners. The same lecturer has taught both of the courses performing the monitoring processes according to the following guidelines:

- Supervisory meetings were scheduled for every alternate week.

- Progress reports were prepared by the student team for each meeting.

- Discussions with the students about the scheduled work.

The project supervisors performed the assessment process according to the following:

- $\quad$ Progress reports assessment: The supervisor received a progress report at each meeting. These reports were assessed during the entire semester.

- Final reports: The project team wrought an engineering report that describes the entire process with a scientific approach.

- Viva: The IEM staff examined each project team member to ascertain his or her knowledge. 


\section{Participants}

The participants were 129 students (82 males and 47 females) in the Industrial Engineering and Management (IEM) department at a school of engineering.

\section{Questionnaire structure}

The evaluation tool included 'preferred' and 'actual' questionnaire forms. The 'preferred' form, reflecting the students' personal perceptions of their preferred learning environment was filled out by the students at the beginning of the course (pretest), while the 'actual' form, showing the students' personal perceptions of their actual learning environment, was filled out at the end of the course (post-test). Our instrument was based on the Science Laboratory Environment Inventory (SLEI) questionnaire (Fraser et al., 1995). The SLEI was validated among 7000 students in university classes in several countries. Fraser et al. suggest that this tool can be used to monitor students' views and to investigate the impact of different environments on student outcomes. Furthermore, it can facilitate the improvement of learning environments

The questionnaire includes 28 questions divided into four categories (subscales). Each category contains seven items. The items are arranged in cyclic order in seven blocks of four questions each. All of the questions have five response alternatives on a Likert scale from 1 to 5 ( 1 - strongly disagree to 5 - strongly agree.). To increase the questionnaire's reliability, some of the questions were worded and scored in the regular manner $(+)$, and some of the questions were worded and scored in the reverse manner $(-)$. The categories were defined as follows:

(a) Student supportiveness - The extent to which students know, help, and are supportive toward each other; for example: Members of my group help me $\left({ }^{+}\right)$.

(b) Independent learning - The extent to which students learn by themselves, including acquaintance with designated software; for example: I don't use special software to work on the project (-).

(c) Integration - The extent to which practical activities are integrated with theory classes; for example: Performing the project helps me to understand the topics that I learned $(+)$.

(d) Guidance - The extent to which guidance contributed to the students; for example: My advisor supports me in performing the project (+).

The Cronbach's Alpha coefficient showing the internal consistency reliability of the questionnaire was 0.815 for the 'preferred' form and 0.855 for the 'actual' form.

\section{Results and Discussion}

Each category included 7 questions, so the number of responses of the 129 students in each category was $129 \times 7=903$. Almost all of the responses in both forms of the questionnaire were at least 3 , whereas responses of 1 and 2 were rare. Table 1 presents the mean, median and the standard deviations (SD) of the 129 participants computed for each category of the preferred and actual form of the questionnaires. 
Table 1. Questionnaires Summary

\begin{tabular}{|c|c|c|c|c|c|c|}
\hline \multirow[t]{3}{*}{ Category } & \multicolumn{2}{|c|}{$\begin{array}{c}\text { Actual form } \\
\text { (Post-test) }\end{array}$} & \multicolumn{4}{|c|}{$\begin{array}{c}\text { Preferred } \\
\text { form(Pre- } \\
\text { test) }\end{array}$} \\
\hline & \multicolumn{2}{|c|}{ Mean } & SD & \multicolumn{2}{|c|}{ Mean } & $\mathrm{SD}$ \\
\hline & \multicolumn{2}{|c|}{ Median } & \multicolumn{4}{|c|}{ Median } \\
\hline (a) & 4.10 & 4 & 0.87 & 4.39 & 5 & 0.68 \\
\hline (b) & 3.32 & 4 & 0.82 & 3.61 & 4 & 0.77 \\
\hline (c) & 3.84 & 4 & 0.89 & 4.06 & 4 & 0.75 \\
\hline (d) & 3.57 & 4 & 0.79 & 3.92 & 4 & 0.77 \\
\hline
\end{tabular}

The median response in both forms of the questionnaire was 4 in almost all of the categories. The normal distribution assumption was rejected using the KolmogorovSmirnov test; therefore, we could not apply the parametric methods and used the nonparametric Wilcoxon signed ranks test. Significant difference between the preferred and actual responses were found in all of the categories $(\mathrm{p}<0.01)$.

Table 2 compares the preferred and actual ranks, presenting the percentage of responses in each category and in the entire questionnaire, where the preferred rank is equal, less or more than the actual rank. For example: in $45.08 \%$ of all the questions in category (a) the students ranked the parallel questions in the 'preferred' and 'actual' forms identically; the percentage in brackets (24.69\%) shows the percentage of responses in which the preferred rank was higher than the actual rank by 1 unit.

Table 2. Students' responses percentage to the preferred form (X) and actual form (Y)

\begin{tabular}{cccccc}
\hline Category & (a) & (b) & (c) & (d) & $\begin{array}{c}\text { Entire } \\
\text { questionnaire }\end{array}$ \\
\hline $\mathrm{X}=\mathrm{Y}$ & 45.08 & 36.33 & 31.40 & 38.76 & 40.12 \\
\hline $\mathrm{X}<\mathrm{Y}$ & 17.72 & 25.13 & 23.14 & 20.15 & 21.53 \\
\hline $\mathrm{X}>\mathrm{Y}$ & 37.20 & 38.53 & 36.54 & 41.09 & 38.34 \\
$(\mathrm{X}-\mathrm{Y}=1)$ & $(24.69)$ & $(24.03)$ & $(25.58)$ & $(26.80)$ & $(25.27)$ \\
\hline
\end{tabular}

The actual rank was at least as the preferred one in most (61.65\%) of all of the responses. In $25.27 \%$ of all of the responses the actual rank was higher than the preferred one by one unit only.

Defining students giving a rank of 4 or 5 as satisfied, the hypothesis that the median rank in the actual form of the questionnaire is at least 4 was tested using Binomial test. The results enable us to confirm the hypothesis $(\mathrm{p}<0.0001)$. 
We present an approach where the practical aspects are implemented by using a real life project within the organizational framework. According to the Anderson and Krathwohl (2001) adaptation of the well-known Bloom Taxonomy of Educational Objectives (Cognitive Domain), the six levels of cognition required in learning are a) to remember b) to understand c) to apply d) to analyse e) to evaluate and f) to create. Students had to exercise all these levels during their project development. For example, one of the projects was to establish a new bus line that would connect the college to the nearest city. The students had to make a feasibility study by surveying the college students and teachers; then they had to plan and design all the logistic aspects related to the new bus line. The final step was to establish a business plan to justify their project.

Moving to the learning environment (that consisted of student supportiveness, independent learning, integration between the practical activities and theory classes, and guidance contribution) positive students' attitudes are important in evaluating a course. Students' positive attitudes strengthen their motivation and interest, and thus promote meaningful learning. The results show that the majority of the students were satisfied with their learning environment; their actual form rank was at least like the preferred form rank. It can be seen that the preferred rank in all the categories is significantly higher than the actual rank. These results are consistent with other studies showing attitudes to actual and preferred learning environments, which revealed that students rank their attitudes to the preferred learning environment higher than the existing one (e.g. Dorman, 2008). The average difference between actual and preferred ranks in the entire questionnaire was 0.3 unit only. According to Fraser (1998) the greater this difference is the more dissatisfied students are with their learning environment. The relatively small gap between actual and preferred learning environments indicates that the students were satisfied with the educational process.

Like the ancient Chinese proverb "Tell me and I will forget. Show me and I may remember. Involve me and I will understand” (Confucius, 450 B.C.), active learning is considered to be an effective learning strategy (Smith et al., 2005).

\section{Conclusions}

We present a training process, based on contextual learning, that ensures the student's updated knowledge and enhance creativity and innovation. The novelty of the presented approach is the use of an embedded project within the program learning process. This project stimulates the student to implement the theoretical knowledge in a practical environment. The combination of academic knowledge with practical know-how can facilitate the engineering student's integration in their future job.

\section{References}

Anderson, L.W. (Ed.), Krathwohl, D.R. (Ed.), Airasian, P.W., Cruikshank, K.A., Mayer, R.E., Pintrich, P.R., Raths, J., \& Wittrock, M.C. (2001). A Taxonomy for Learning, Teaching, and Assessing: A Revision of Bloom's Taxonomy of Educational Objectives, Complete edition, New York: Longman.

Binnie, A. (2004). Development of a senior physics syllabus in New South Wales. Physics Education, 39(6), 490-495.

Caine, R.N. and Caine, G. (1991). Making connections: Teaching and the human brain. Alexandria, VA: Association for Supervision and Curriculum Development. 
Dewey, J. (1916). Democracy and education: an introduction to the philosophy of education. New York: Macmillan.

Dorman, J. P. (2008). Using student perceptions to compare actual and preferred classroom environment in Queensland schools. Educational Studies, 34, 299-308.

Fraser, B.J., Giddings, G.J., and McRobbie, C.J. (1995). Evolution and validation of a personal form of an instrument for assessing science laboratory classroom environments. Journal of Research in Science Teaching, 32, 399-422.

Fraser B. J. (1998). Science learning environments: Assessment, effects and determinants. In B.J. Fraser and K.G. Tobin (Eds.), International handbook of science education (pp. 527-564). Dordrecht, The Netherlands: Kluwer.

Klassen, S. (2006). A theoretical framework for contextual science teaching. Interchange, 37(1-2), 31-62.

Kukliansky, I. \& Eshach, H. (2014). Evaluating a Contextual-Based Course on Data Analysis for the Physics Laboratory. Journal of Science Education and Technology, 23(1), 108-115.

Rivet, A.E., and Krajcik, J.S. (2008). Contextualizing instruction: Leveraging students' prior knowledge and experiences to foster understanding of middle school science. Journal of Research in Science Teaching, 45(1), 79 -100.

Roth, W.M., and Roychoudhury, A. (1993). The development of science process skills in authentic contexts. Journal of Research in Science Teaching, 30(2), 127-152.

Rozenes, S., \& Vitner, G. (2009). The training methodology of project management office (PMO) personnel. Industrial and Commercial Training, 41(1), 36-42.

Shelley-Tolbert, C.A., Conroy, C.A., and Dailey, A. L. (2000). The move to agriscience and its impact on teacher education in agriculture. Journal of Agricultural Education, 41(4), 51-61.

Smith, A.J. (2000). The Washington state consortium for contextual teaching and learning .Center for the Study and Teaching of At-Risk Students, Seattle.

Smith, K.A., Sheppard, S.D., Johnson, D.W., and Johnson, R.T. (2005). Pedagogies of Engagement: Classroom-Based Practices, Journal of Engineering Education, 94(1), $87-101$. 